\title{
DIAGNOSTIC YIELD OF ABRAMS PLEURAL BIOPSY IN PATIENTS PRESENTING WITH LYMPHOCYTIC EXUDATIVE PLEURAL EFFUSION.
}

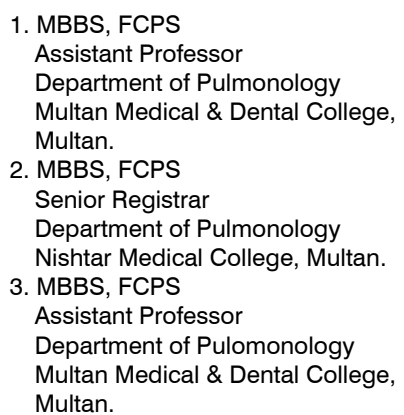

Corresponding Author:

Dr. Kashif Sardar

MBBS, FCPS

Department of Pulmonology

Multan Medical \& Dental College

Multan.

dr.kashifsardar@gmail.com

Article received on:

22/11/2018

Accepted for publication:

25/03/2019

Received after proof reading: $25 / 06 / 2019$

\begin{abstract}
Kashif Sardar ${ }^{1}$, Nasir Javed ${ }^{2}$, Sufyan Saleem Safdar ${ }^{3}$
ABSTRACT... Pleural effusion is the one of the most common clinical conditions encountered in pulmonology clinics and the routinely performed tests on pleural fluid do not provide definitive diagnosis in majority of the cases. Medical thoracoscopy with pleural biopsy under direct vision of the abnormal area provides the highest diagnostic yield. Abrams closed needle pleural biopsy is a conventional and cheaper procedure which can help in the definitive diagosis in cases of undiagnosed pleural effusion. To determine the diagnostic yield of abrams pleural biopsy in patients presenting with lymphocytic exudative pleural effusion. Study Design: Cross Sectional Study. Setting: Department of Pulmonology Nishtar Hospital Multan; Tertiary care hospital of 1180 beds. Period: Six months. Materials and Methods: There were 145 patients diagnosed with lymphocytic exudative pleural effusion. Results: Of these 145 study cases, males were $83 / 145(57.2 \%)$ whereas females were $62 / 145(42.8 \%)$. Mean age of our patients was $41.62 \pm 13.63$ years while mean duration of illness was $7.0 \pm 3.24$ weeks. When the frequencies of various diagnosis established on the basis of histopathology results obtained from the tissue specimen obtained with Abrams pleural biopsy was noted, Tuberculosis was the major cause of lymphocytic exudative pleural effusion as its frequency was noted to be in $81 / 145(55.9 \%)$ of our patients while malignancy was present in $26 / 145(17.9 \%)$ of our study cases whereas the histopathology turned out to be inconclusive in $38 / 145(26.2 \%)$ showing non-specific inflammation. The diagnostic yield of Abrams pleural biopsy turned out to be $73.8 \%$ whereas it was unable to establish diagnosis in $26.2 \%$. Conclusion: Abrams needle pleural biopsy is simple, reliable and safe method of diagnosis with a good diagnostic yield. Routine use of this procedure in patients with lymphocytic exudative pleural effusion can lead to a definitive diagnosis in majority of patients.
\end{abstract}

Key words: $\quad$ Abrams Needle Pleural Biopsy, Diagnostic Yield, Pleural Effusion.

Article Citation: Sardar K, Javed N, Safdar SS. Diagnostic yield of abrams pleural biopsy in patients presenting with lymphocytic exudative pleural effusion. Professional Med J 2019; 26(7):1014-1019. DOI: 10.29309/TPMJ/2019.26.07.1389

\section{INTRODUCTION}

Pleural effusion is a frequently encountered problem in respiratory clinics and despite advances in the cytological, biochemical and microbiological tests which are done on the pleural fluid the etiological diagnosis cannot be established in majority of patients, which are then labelled as undiagnosed exudative pleural effusions. ${ }^{1}$ Prevailing causes of lymphocytic exudative pleural effusions include malignancy, tuberculosis, connective tissue diseases, sarcoidosis and sometimes pulmonary embolism. ${ }^{2,3,4}$ Pleural fluid cytology in malignant pleural effusion turns out to be positive in $40 \%$ $80 \%$ of the cases and pleural fluid culture for acid fast bacilli is positive in less than $40 \%$ cases of tuberculous effusions. When closed pleural biopsy is performed with histological examination and culture of the obtained pleural tissue the diagnostic yield for tuberculosis increases to 80 to $90 \% .^{5}$ This signifies that closed pleural biopsy plays an important role in differentiating tuberculous from malignant pleural effusion.

A Study conducted by Ihsanullah in Pakistan has shown pleural biopsy to be conclusive in $95 \%$ cases which include $56.7 \%$ for TB and $40 \%$ for malignancy. ${ }^{6}$ In two other national studies pleural biopsy showed positive results in $71.62 \%$, and $63.29 \%$ of cases that include $52.71 \%$, and $42 \%$ for TB whereas $18.91 \%$, and $36 \%$ for malignancy respectively. ${ }^{4,7}$ 
A study conducted by Gupta et al. in India established that out of 48 cases, results of closed pleural biopsy were conclusive in $62.2 \%$ of cases. Of these $43.8 \%$ revealed Tuberculosis, $29.2 \%$ Malignancy, $12.5 \%$ Paramalignant. $^{8}$

Patients with lymphocytic exudative type of pleural effusion are a common presentation in tertiary care hospitals. Pakistan being endemic country for tuberculosis, most of such patients are given antituberculous therapy without confirmation of diagnosis. However differential diagnosis includes malignancy, autoimmune disorders, etc. In order to rationalize our management we intend to look into the role of pleural biopsy using Abram's pleural biopsy needle. Various studies have shown high yield of pleural biopsy using Abram needle in suspected tuberculous pleural effusions, however in malignant pleural effusion, its yield is moderate. Patients who remain undiagnosed on this procedure need further diagnostic workup using medical pleuroscopy or video assisted thoracoscopic (VATS) pleural biopsy. However these relatively advanced procedures are only available in few centers of Pakistan and a number of patients remain undiagnosed due to either lack of facility for pleuroscopic biopsies or lack of expertise.

We are conducting this study to assess the diagnostic yield of Abrams pleural biopsy as there is no data available in our local setup.

\section{MATERIALS AND METHODS}

Study Setting

Department of Pulmonology Nishtar Hospital Multan; Tertiary care hospital of 1180 beds.

Duration of Study

Six months.

Study Design

Cross Sectional Study.

Sample Size

145 patients.

Sampling Technique

Non probability consecutive sampling.

Inclusion Criteria

Patients of both genders of age 18-60 years with a diagnosis of lymphocytic exudative Pleural Effusion.

Exclusion Criteria

Patients with Transudative pleural effusion, Empyema, Neutrophilic Effusion, Pleural Fluid Thickness $<3 \mathrm{~cm}$ on USG chest, Bleeding Diathesis and Local Skin Infection at the site of biopsy were excluded from the study.

\section{Data Collection Procedure}

One hundred and forty five (145) consecutive patients with diagnosed Lymphocytic exudative effusion attending the Pulmonology indoor and outpatient department were included in the study. Permission was taken from institutional ethical committee to conduct this study. Written Informed consent was taken from patients after thoroughly explaining the procedure. Those patients who fulfilled the inclusion and exclusion criteria closed pleural biopsy was performed with full aseptic measures and under local anesthesia by the researcher. Closed pleural biopsy was done with Abrams needle to obtain 3-4 biopsy samples. The samples were properly labeled and sent in formalin jar to Shaukat Khanam Laboratory for histopathological examination. All the demographic data and results of histopathology were noted in the proforma.

\section{RESULTS}

There were 145 patients diagnosed with lymphocytic exudative pleural effusion. Of these 145 study cases, males were 83/145 (57.2\%) whereas females were 62/145 (42.8\%) (Figure-1). Mean age of our patients was $41.62 \pm 13.63$ years (minimum 18 to maximum 66 years). Mean duration of illness was $7.0 \pm 3.24$ weeks (minimum 3 weeks to maximum 14 weeks).

\section{Gender distribution}

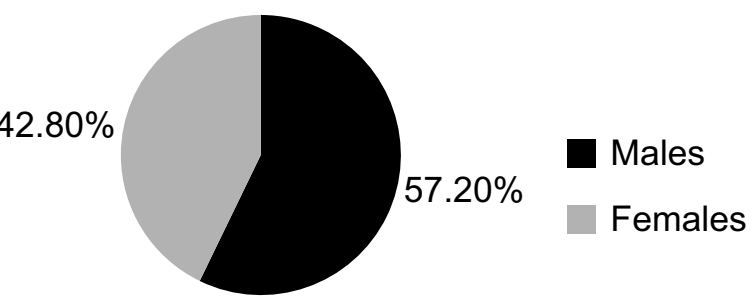

Figure-1. Gender distribution in the study population. 
Among the clinical features Fever was present in 134 (92.4\%), chest pain in 114 (78.6\%), cough in $113(77.9 \%)$, constitutional symptoms in 115 $(79.3 \%)$, shortness of breath was noted in 130 $(89.7 \%)$ of our patients. Haemoptysis was not noted in none of the patients. Pleural effusion was seen on the right side in $81 / 145(55.9 \%)$ while it was on the left side in $64 / 145$ (44.1\%).

\begin{tabular}{|c|c|c|}
\hline \multirow{2}{*}{ Gender } & Males & $83(57.2 \%)$ \\
\hline & Females & $62(42.8 \%)$ \\
\hline \multirow[b]{2}{*}{ Mean } & Age & $41.62 \pm 13.63$ \\
\hline & $\begin{array}{l}\text { Duration of } \\
\text { illness (Weeks) }\end{array}$ & $7.0 \pm 3.24$ \\
\hline \multirow{6}{*}{ Clinical Features } & Fever & $134(92.4 \%)$ \\
\hline & Chest Pain & $114(78.6 \%)$ \\
\hline & Cough & 113 (77.9\%) \\
\hline & Constitutional & 115 (79.3\%) \\
\hline & Dyspnea & $130(89.7 \%)$ \\
\hline & Hemoptysis & Nil \\
\hline \multirow{2}{*}{ Side of Effusion } & Right sided & 81 (55.9\%) \\
\hline & Left sided & 64 (44.1\%) \\
\hline
\end{tabular}

When the frequencies of various diagnosis established on the basis of histopathology results obtained from the tissue specimen obtained with Abrams pleural biopsy was noted, Tuberculosis was the major cause of lymphocytic exudative pleural effusion as its frequency was noted to be in $81 / 145$ (55.9\%) of our patients while malignancy was present in $26 / 145$ (17.9\%) of our study cases. Whereas the histopathology turned out to be inconclusive in 38/145 (26.2\%) showing non-specific inflammation (Figure-2). The diagnostic yield of Abrams pleural biopsy turned out to be $73.8 \%$ whereas it was unable to establish diagnosis in $26.2 \%$. (Figure-3)

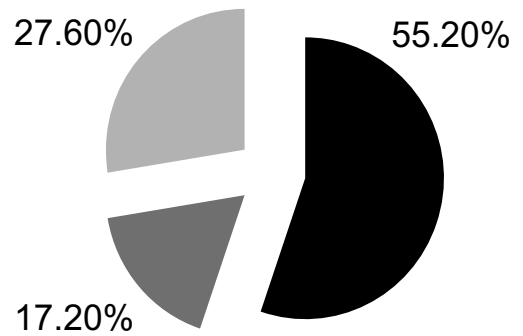

Tuberculosis

Adenocarcin oma

Non-specific

Figure-2. Frequencies of various diagnosis established on histopathology results.

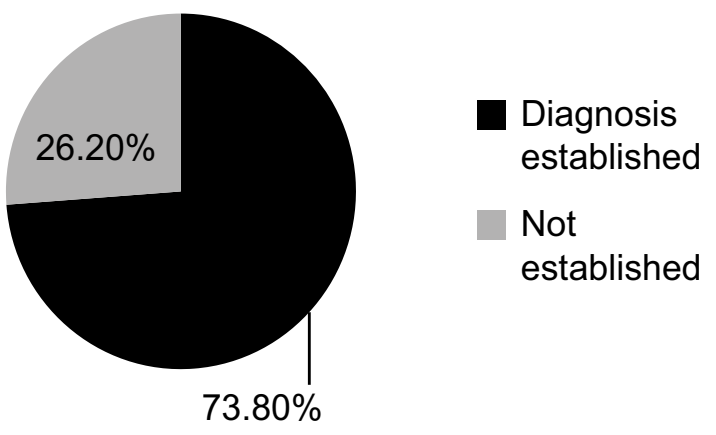

Figure-3. Diagnostic yield of Abrams pleural biopsy.

When the effect of gender was noted it was found that among 26 females, tuberculosis was found in $30 / 62$ (48.4\%), malignancy was found in $11 / 62(17.7 \%)$ whereas no specific diagnosis was established in 21/62 (33.87\%). In comparison among total 83 male patients, tuberculosis was found in $51 / 83(61.4 \%)$, malignancy was found in $15 / 83(18.02 \%)$ while no specific diagnosis was established in 17/83 (20.4\%). When chi-square test was applied the difference among male and female patients was statistically non-significant with a p-value of 0.173 . (Table-II).

\begin{tabular}{|c|c|c|c|c|}
\hline & TB & Malignancy & Nonspecific & P-Value \\
\hline $\begin{array}{l}\text { Male } \\
(n=83)\end{array}$ & $\begin{array}{c}51 \\
(61.4 \%)\end{array}$ & $\begin{array}{c}15 \\
(18.02 \%)\end{array}$ & 17 (20.4\%) & \multirow{3}{*}{0.174} \\
\hline $\begin{array}{l}\text { Females } \\
(n=62)\end{array}$ & $\begin{array}{c}30 \\
(48.4 \%)\end{array}$ & $\begin{array}{c}11 \\
(17.7 \%)\end{array}$ & $\begin{array}{c}21 \\
(33.87 \%)\end{array}$ & \\
\hline Total & 81 & 26 & 38 & \\
\hline
\end{tabular}

When the effect of side of effusion on established diagnosis was noted it was found that among patients with right sided pleural effusion among a total of 81 patients Tuberculosis was identified in $48 / 81$ (59.2\%), malignancy in 13/81 (16.04\%) while no specific diagnosis was established in $20 / 81$ (24.6\%). In comparison among 64 patients with left sided pleural effusion tuberculosis was established in $33 / 64$ (51.6\%), malignancy was established in 13/64 (20.3\%) whereas no specific diagnosis was established in 18/64 (28.1\%). The difference was found to be clinically nonsignificant $(p$-value $=0.637)$. (Table-III) 


\begin{tabular}{|l|c|c|c|c|c|}
\hline & TB & Malignancy & Nonspecific & Total & $\begin{array}{c}\text { P- } \\
\text { Value }\end{array}$ \\
\hline \begin{tabular}{l|l|l|l|} 
Right \\
sided \\
$(n=81)$
\end{tabular} & $\begin{array}{c}48 \\
(59.2 \%)\end{array}$ & $\begin{array}{c}13 \\
(16.04 \%)\end{array}$ & $\begin{array}{c}20 \\
(24.1 \%)\end{array}$ & 81 & \\
\hline $\begin{array}{l}\text { Left } \\
\text { sided } \\
(n=64)\end{array}$ & $\begin{array}{c}33 \\
(51.6 \%)\end{array}$ & $\begin{array}{c}13 \\
(20.3 \%)\end{array}$ & $\begin{array}{c}18 \\
(28.1 \%)\end{array}$ & 64 & \\
\hline Total & 81 & 26 & 38 & 145 & \\
\hline
\end{tabular}

When the effect of age on the diagnostic outcome was noted it was found that there were 80 patients in the age group $<45$, out of these tuberculosis was identified in $53 / 80$ (66.25\%), malignancy was found in $10 / 80$ (12.5\%) whereas non-specific inflammation was found in $17 / 80$ (21.25\%) patients. There were 65 patients in age group $\geq$ 45 , tuberculosis was found in $32 / 65$ (49.23\%), malignancy was found in 14/65 (21.54\%) whereas non-specific inflammation was found in 19/65 (29.23\%). (Table-IV).

\begin{tabular}{|c|c|c|c|c|}
\hline & TB & Malignancy & Nonspecific & P-Value \\
\hline $\begin{array}{l}\text { Age }<45 \\
(n=80)\end{array}$ & $\begin{array}{c}53 \\
(66.25 \%)\end{array}$ & $\begin{array}{c}10 \\
(12.5 \%)\end{array}$ & $\begin{array}{c}17 \\
(21.25 \%)\end{array}$ & \multirow{3}{*}{0.174} \\
\hline $\begin{array}{l}\text { Age } \geq 45 \\
(n=65)\end{array}$ & $\begin{array}{c}32 \\
(49.23 \%)\end{array}$ & $\begin{array}{c}14 \\
(21.54 \%)\end{array}$ & $\begin{array}{c}19 \\
(29.23 \%)\end{array}$ & \\
\hline Total & 85 & 24 & 36 & \\
\hline \multicolumn{5}{|c|}{$\begin{array}{c}\text { Table-IV. Effect of side of effusion on the diagnostic } \\
\text { outcome }\end{array}$} \\
\hline
\end{tabular}

\section{DISCUSSION}

Lymphocytic exudative pleural effusion is a common clinical problem in respiratory medicine clinics all over the world. Conclusive diagnosis of the cause of lymphocytic exudative pleural effusion is a challenging problem which requires a number of costly investigations done on pleural fluid with a relatively low diagnostic yield. In such patients pleuroscopy with pleural biopsy under direct vision is recommended to reach a definite diagnosis. However, the invasiveness, cost, requirement of expertise and sterilization as well as unavailability of the equipment limits its use in resource limited settings. Alternatively, blind Pleural biopsy can be performed in such patients which can provide a definite tissue diagnosis. This procedure has been used routinely in the past before the advent of fiber-optic pleuroscopes. Its use is now considered out-dated because the diagnostic yield of blind closed pleural biopsy is reported to be significantly lower than that can be achieved with pleuroscopic biopsy.

It requires careful evaluation for tuberculosis, malignancy (i.e. lung cancer, lymphoma, and metastasis) and some uncommon diseases like sarcoidosis etc. It is usually treated empirically with anti-TB treatment but considering the increasing incidence of malignancies especially lung cancer definitive diagnosis should always be considered. In patients aged over 60 years, malignant diseases should be considered the most probable cause, although reactivation of previous TB may also present as lymphocytic exudative Pleural effusion. 9,14,15

Our study comprised of a total of 145 patients diagnosed with lymphocytic exudative pleural effusion males were $83 / 145$ (57.2\%) whereas females were 62/145 (42.8\%). Various authors have reported that lymphocytic exudative pleural effusion being more common among male patients than females. Ihsanullah reported $74 \%$ male patients and $26 \%$ female patients. ${ }^{6}$ Rehan et $\mathrm{al}^{10}$ reported $65 \%$ male patients with pleural effusion and $35 \%$ female patients, these findings are close to that of our study results.

Mean age of our study cases was $41.62 \pm$ 13.63 years (minimum age was 18 years and maximum age was 66 years). Similar results have been reported by Ihsanullah et al. ${ }^{6}$ Rehan et al ${ }^{10}$ reported mean age of pleural effusion patients to be $44.82 \pm 17.71$ years, which is close to our study results.

Mean duration of illness was $7.0 \pm 3.24$ weeks (minimum 3 weeks to maximum 14 weeks). Our study results have shown that majority of patients i.e. 131 (90.3\%) presented within 6 weeks.

Fever was present in 134 (92.4\%) of our study cases, chest pain in 114 (78.6\%), cough in 113 (77.9\%), constitutional symptoms in 115 (79.3\%), shortness of breath was noted in 130 (89.7\%) of 
our study cases. Haemoptysis was not noted in any of our study cases i.e. (0\%). A study conducted by Rehan et $\mathrm{al}^{10}$ reported dyspnea frequency as $82 \%$ (which was predominant as well), this value is close to our findings, however in our study fever was leading presenting complaint which was $80 \%$ as reported by Rehan et al. ${ }^{10}$ Rehan et al reported that $77 \%$ of their patients presenting with cough which is also similar to our study results. Ihsanullah et al $^{12}$ reported similar findings.

In majority of our study cases, pleural effusion was seen on the right side i.e. $89(61.4 \%)$ while it was on the left side $56(38.6 \%)$ of our study cases. Similar findings have been reported by Ihsanullah. ${ }^{6}$ Rehan et al $^{10} 58 \%$ on the right side and $30 \%$ on the left side, these findings are close to that of our study results.

Diagnostic yield of the Abrams needle pleural biopsy among targeted population has been reported to be variable ranging from below $60 \%$ to as high as $95 \%$ of the patients. ${ }^{6}$ Our study results report the diagnostic yield to be $73.8 \%$ which are close to the diagnostic yield reported by Rajawat et al which was $71.2 \%{ }^{11}$

Tuberculosis was the major cause of lymphocytic exudative pleural effusion as its frequency was noted in $81 / 145$ (55.9\%) of our study cases while malignancy was present in 26/145 (17.9\%) of our study cases. Similar findings have been reported by many different researchers in which TB was the major cause of exudative lymphocytic pleural effusion. ${ }^{6,7,10,12,13}$

Our study results are in compliance with most of the national and international studies which also reported a good diagnostic yield of the procedure and TB being leading cause of pleural effusion.

\section{CONCLUSION}

Abrams needle pleural biopsy in lymphocytic exudative pleural effusion is simple, reliable and safe method of diagnosis with diagnostic yield in majority of the cases as observed in our study. Tuberculosis was the leading cause of pleural effusion in our study.

Copyright@ 25 Mar, 2019.

\section{REFERENCES}

1. Hira HS, Ranjan R. Role of percutaneous closed needle pleural biopsy among patients of undiagnosed exudative pleural effusion. Lung India $2011 ; 28(2): 101-4$.

2. Zablockis R, Nargela R. Diagnostic value of pleural fluid cytologic examination. Medicina 2002; 38(12):1171-8.

3. Shaikh SJ, Memon SAB. The etiology of pleural effusion in children: Hyderabad experience. Pak J Med Sci. 2007; 23:86-7.

4. Anwar R, Farooqi Jl. Incidence of malignancy in case of lymphocytic exudative pleural effusion, as revealed by percutaneous pleural biopsy. Med Channel 2005; 11:59-61.

5. Seibert AF, Haynes $J$ Jr, Middleton R, Bass JB Jr. Tuberculous pleural effusion. Twenty-year experience. Chest journal 1991; 99(4):883-6.

6. Ihsanullah, Khan $\mathrm{N}$, Jadoon $\mathrm{H}$, Zaman $\mathrm{M}$, Ahmed A. Yield of Abrams needle pleural biopsy in exudative pleural effusion. J Ayub Med Coll Abbottabad 2009; 21(1):116-8

7. Khurram M, Jaffery $A H$, Khar $H$ tul B, Malik M F, Burki $U$ $F$, KhanB A, et al. Evaluation of lymphocytic exudative pleural effusion with pleural biopsy. J Coll Physicians Surg Pak 2002; 12(2):74-7.

8. James P, Gupta R, Christopher DJ, Balamugesh T. Evaluation of the diagnostic yield and safety of closed pleural biopsy in the diagnosis of pleural effusion. Indian J Tuberc 2010; 57(1):19-24.

9. Solooki M, Miri M. Approach to undiagnosed exudative pleural effusion: the diagnostic yield of blind pleural biopsy. Caspian J Intern Med. 2013; 4(2):642-7.

10. Rehan M, ALam MT, Aurangzeb M, Imran K, Farrukh $S Z$, Masroor $M$, et al. Frequency of various disease in patients with pleural effusion. Gomal J Med Sci. 2013; 11:78-83.

11. Rajawat GS, Batra S, Takhar RP, et al. Diagnostic yield and safety of closed needle pleural biopsy in exudative pleural effusion. Avicenna J Med. 2017; $7(3): 121-4$.

12. Khaliq MR. Pleural biopsy by Abrams punch needle pattern and frequency of histopathological lesions encountered in patients with exudative pleural effusion. Ann Abbasi Shaheed Hosp Karachi Med Dent Coll. 2003; 8(1):6-11. 
13. Shah SAA, Iqbal Z, Qamar MA, Khattak MF. Diagnostic value of Abrams punch pleural biopsy in exudative pleural effusion. J Med Sci. 2011; 19(2):86-8.

14. Devkota KC; Chokhani R; Gautam S. Diagnostic yield of pleural biopsy in exudative pleural effusion. Nepal Med Coll J. 2014; 16(1):13-16.
15. Hooper C, Lee YC, Maskell N. BTS Pleural Guideline Group. Investigation of a unilateral pleural effusion in adults: British Thoracic Society pleural disease guideline 2010. Thorax. 2010; 65:4-17.

\begin{tabular}{|c|c|c|c|}
\hline \multicolumn{4}{|c|}{ AUTHORSHIP AND CONTRIBUTION DECLARATION } \\
\hline Sr. \# & Author-s Full Name & Contribution to the paper & Author $=$ s Signature \\
\hline 1 & Kashif Sardar & 1st Author & mmi \\
\hline 2 & Nasir Javed & 2nd Author & $N=0$ \\
\hline 3 & Sufyan Saleem Safdar & 3rd Author & 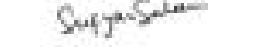 \\
\hline
\end{tabular}

